\title{
Microstructure and Corrosion Properties of Orthodontic Brackets by Laser Treatment
}

\author{
Xiaoyan Zhang ${ }^{1+}$, Yu Song ${ }^{2+}$, Xinhong Wang ${ }^{3, *}$ \\ ${ }^{1}$ Department of Orthodontics, Capital Medical University School of Stomatology, Beijing \\ 100050, China. \\ ${ }^{2}$ Department of Orthodontics, Qingdao Stomatological Hospital, Qingdao 266001, China. \\ ${ }^{3}$ Key Laboratory for Liquid-Solid Structural Evolution \& Processing of Materials Ministry of \\ Education, Shandong University, Jinan 250061, China. \\ ${ }^{+}$These two authors are both the co-first author of the paper. \\ *E-mail: xinhong2016@sina.cn
}

doi: $10.20964 / 2017.01 .24$

Received: 29 February 2016 / Accepted: 18 October 2016 / Published: 12 December 2016

The austenitic stainless steel AISI 316L has been chosen as the material for orthodontic bracket. This paper reported our studies on the surface of the stainless steel $316 \mathrm{~L}$ treated by laser heat input. We substantiated the effects of laser heat input including the microstructure, microhardness and corrosion resistance. The results showed that laser surface treatment not only refined grain, but also enhanced microhardness of the $316 \mathrm{~L}$ orthodontic bracket at certain heat input. Through X-ray diffraction with $\mathrm{Cu}-\mathrm{K} \alpha$ radiation, $\mathrm{Cr}_{0.19} \mathrm{Fe}_{0.7} \mathrm{Ni}_{0.11}$ was the main component phase. The corrosive characteristic of $316 \mathrm{~L}$ orthodontic bracket with $E=0.67 \mathrm{~kJ} / \mathrm{cm}$ was higher than that of the $316 \mathrm{~L}$ without heat treatment.

Keywords: Orthodontic bracket, Laser heat input, Microstructure, Corrosion resistance.

\section{FULL TEXT}

(C) 2017 The Authors. Published by ESG (www.electrochemsci.org). This article is an open access article distributed under the terms and conditions of the Creative Commons Attribution license (http://creativecommons.org/licenses/by/4.0/). 